\title{
Direito e Teoria do Estado
}

\author{
Miguel Reale \\ (Catedrático de Fizosofia do Direito)
}

\section{Noções Gerais}

A Teoria Geral do Estado é ciência que, sob alguns aspectos, de novo só tem o nome. Tal ordem de estudos Aristóteles denominou-a Política, na acepção lata dêste termo, e dela tratou também Platão em sua República e em Das Leis. O que distingue a moderna Teoria do Estado, no entanto, é uma detcrminação mais precisa de seu objeto. com maior riqueza de dados e mais rigor metódico, o que é prossibitado também pela especificação dos campos de análise da História, da Sociologĩa, da Etnografia e do Direito.

Para nós Teoria do Estado e Ciência Política são uma e a mesma coisa, e cremos assistir razão aos ingleses por preferirem o segundo ao primeiro termo para indicar o sistema de pesquizas concernentes à instituição estatal.

A palavra "Politíca" é mais latina, mais nossa, de maneira que não havia necessidade alguma de traduzir a expressão alemã correspondente a Teoria Geral do Estado (Allgemeine Staatslehre), que, no entanto, já adquiriu entre nós fôros de cidadania.

Por qual motivo aquela palavra passou a significar "arte de bem governar" ou de realizar as finalidades particulares do Estado? Porventura Aristóteles entendeu a "Política" naquela acepção mínima? Vejamos.

Deu-se com a Teoria do Estado ou com a Política, um fenômeno que se verifica com outras esferas de indagações. Podemos dizer que o conhecimento humano se desenvolve 
entre duas visões unitárias, entre as quais se verifica um processo de análise è de discriminação, indo-se, como diz Renan, de uma "síntese amorfa" originária a uma "síntese diferençada".

A visão do Estado que Aristóteles teve - visão genial que lançou as bases da ciêncía - foi, entretanto, necessáriamente, uma visão global e amorfa, na qual as partes componentes não se situavam de maneira clara e distinta. Com o termo Política, Aristóteles pretendeu indicar o estudo da realidade social e política em tôdas as suas expressões, inclusive as morais, econômicas e religiosas. A Politica surge aos olhos do estagirita como a ciência por excelência, ou a arquitetônica das ciências, porque abrange o homem na totalidade de suas manifestações como ser social, em tôdas as suas atividades, religiosas, morais, econômicas e jurídicas. Merece lembrada a advertência do "maestro di color che sanno": "O bem é digno de ser amado mesmo por um só homem; mas è mais belo e divino quando o é por Nações e por Estados. O bem supremo periencerá (pois) à ciência suprema, diretora por excelência da ação humana. E parece ser a Política" (Ética nicomachea, I, 2, 1094).

Vê-se, por conseguinte, que o termo Política, para Aristóteles, é denso de significado, abrangendo tôdas as formas do viver coletivo. É o Estado, de certa forma, o valor supremo que resume em si todos os valores. Esta é a concepção que Aristóteles tem da Política, vendo no Estado ao mesmo tempo um meio e um fim. (1)

Mas esta foi uma visão inicial, uma visão primeira, envolvendo problemas suscetíveis de serem postos de maneira específica e autônoma. Daí ter-se verificado um longo trabalho de análise, em que cada um dos aspectos do Estado,

(1) Cif. Mrguel Reale - O Estado Moderno e Atualidades de um mundo antigo, assim como Filosofia do Direito, vol I, t. II. 
ou, melhor, da vida social (porque, para Aristóteles, o Estado é a própria sociedade) foi sendo distinta dos outros, passando a constituir objeto de estudos diferentes. Assim, a atividade religiosa aos poucos não se confundiu mais com a atividade moral, e o mesmo se deu com as normas jurídicas, especialmente por essa obra formidável de "especialização ou de categorização do jurídico", que foi realizada pelos jurisconsultos romanos.

Os juristas romanos foram os fundadores da Ciência do Direito, porque do grande complexo das normas sociais separaram as normas jurídicas e crearam a ciência especial destinada a estudar êste campo de regras. Ora, a separação do Direito como ciência autônoma verificou-se como um desmembramento da Política, na acepção primeira de Aristóteles. De igual modo, verificaram-se vários desmembramentos no decorrer da história. A Economia deixou de ser economia do Estado para ser "Ciência Economica" e, ainda hoje, a expressão Economia Política nos relembra a formação inicial da ciência.

Desmembraram-se, portanto, da Política, várias ciências particulares: a Economia, o Direito, a Sociologia, a Ciência das Finanças, etc. No próprio Direito, ocorreram discriminações: o Direito Civil, o Comercial, o Administrativo, o Internacional e assim por diante.

Aos poucos, a Política passou a ser vista apenas como arte de bem governar, perdendo-se, em razão daquele prodigioso trabalho de análise, a visão do conjunto, a compreensão completa da instituição Estado.

Mas à medida que se desenrila o trabalho de análise, o espírito humano sente necessidade de recompor a unidade primitiva. Foi assim que ressurgiu, no fim do século passado, esta ciência sintética que é a Teoria Geral do Estado ou a Ciência Política. Ł́ a ciência unitária do Estado. Na Teoria de Estado ou na Política (lato sensu), não vamos estudar o Estado como unidade amorfa, indiferençada, mas 
como unidade que abrange partes já analiticamente apreciadas.

Nâo se pense, no entanto, que a Teoria do Estado seja uma sistematização de resultados, ou uma Enciclopédia das Ciências do Estado, consoante explicação positivista vulgarizada no Brasil, e que ainda hoje possue adeptos (2).

Se há uma Teoria do Estado autônoma, é porque há no Estado algo de irredutível ao campo das pesquizas singulares: é a determinação do "ser" mesmo do Estado, de sua natureza, dos elementos que nos dão a sua consistência e estrutura, elementos êsses que poderão depois, por abstração, ser objeto de indagações distintas.

Dá-se com o Estado o mesmo que ocorre com o Direito, ou seja, há necessidade de uma Ontognoseologia estatal, no. sentido de se determinar, de início, antes de qualquer indagação especial, a natureza do "político" como tal. É nessa ordem de estudos que o Estado, graças a uma análise fenomenológico-histórica, surge com uma entidade tridimensional consistindo no factum social de uma convivência ordenada (substratum social e formas do poder político) segundo um sistema de normas (ordenamento jurídico) na medida e em função de um mundo de valores (dimensão axiológicopolítica).

Completa-se, desse modo, o trabalho de conhecimento da realidade estatal. Isto, porém, não quer dizer que não se prossiga no trabalho de análise.

(2) Longe de identificar Filosofia Politica e Teoria Geral do. Estado, como interpretou Nelson DE Sousa Sampaio (Ideologia $e$ Ciência Política, Bahia, 1953, pág. 304, n. 510) penso que cada uma daquelas ordens de sabier possui objeto próprio. Embora fiél à discriminação das 3 partes especiais da Teoria do Estado apontadas em Teoria do Direito e do Estado, São Paulo, 1940, págs. 107 e segs., julgo necessário completar meu pensamento, anteponido-lhe uma parte Geral, que, como se diz no texto, denomino Ontognoseologia estatal. 
Análise e sintese são fluxo e refluxo do conhecimento humano. As várias análises feitas pelo jurista, pelo economista, pelo moralista etc. reclamavam uma visão unitária do Estado e punham, como dissemos, o problema da realidade estatal como algo insuscetivel de ser reduzido a uma simples justaposição de perspectivas particulares.

Não é certo, pois, dizer que a Política seja mero conjunto das ciências do Estado. Isto é reduzí-la a um simples nome, em uma forma tardia de nominalismo.

A Teoria do Estado é ciência que tem objeto próprio, apresentando três faces distintas, perfeitamente caracterizadas: a face jurídica, que é objeto da Teoria jurídica do Estado; a face social, que é objeto da Teoria social do Estado; e a face teleológica que é o objeto da Teoria política do Estado, em cujo âmbito se inclui a Política do Direito.

A Teoria do Estado ou Ciência Política, não é, desse modo, o conjunto das ciências do Estado, mas a ciência daquilo que no Estado há de comum ou de constante, suscetível de condicionar expressôes diversas, objeto das ciências particulares. Não é, pois, totalização aritmética de saberes sôbre o Estado, mas o saber sôbre o Estado em sua consistência ou estrutura objetiva, condicionando quaisquer possíveis indagações especiais sôbre a realidade estatal.

\section{O Objeto próprio da Ciencia Política ou Teoria do Estado.}

Estado, no sentido técnico deste termo, só existe onde uma convivência, estabelecida em um determinado território, esteja sujeita a um complexo de regras que se denomina "ordenamento", sendo êsse ordenamento garantido por um poder uno. Sem unidade de poder não há Estado, embora possa ser multipla a forma de seu exercício, como acontece em uma Federação. Daí podermos dizer que $\circ$ Estado é a organização de uma convivência em uma unidade de poder. 
Com a palavra Estado verifica-se fenômeno análogơ ao já observado a propósito de outros termos fundamentais das ciências jurídicas e morais. São termos elásticos que, através do tempo, vão recebendo conteúdos vários, passando a ter acepções diversas. Lendo certos autores, temos a impressão de que êles reduzem o Estado à sociedade em geral. Para outro6, ao contrário, a palavra Estado possue acepção muito restrita, para indicar exclusivamente o Govêrno. 'E' celebre a teoria de Leon Duguit, para quem o Estado não é outra coisa senão o Govêrno, o complexo dos governantes.

Entre êsses dois extremos, entre aqueles que reduzem o Estado à sociedade e os que reduzem o Estado ao Govêrno, parece-nos razoável concebê-lo como sociedade, sim, mas como uma forma especial de sociedade, a sociedade enquanto organizada em uma unidade de poder. Há Estado onde existe organização de poder, de um poder que declare Direito Positivo em última instância, o que é a característica essencial da soberania, consoante já expusemos, desde 1940, em Teoria do Direito e do Estado.

Ora, sendo o Estado uma sociedade organizada em uma unidade de poder, podemos focalizar essa instituição segundo três pontos de vista distintos: ou apreciamos o "substractum" social, o embasamento soeial do Estado; ou a forma jurídica de sua organização; ou então as suas finalidades assim como os meios ou processos técnicos de alcançá-los.

As organizações sociais surgem em razão de fins e em uma funcionalidade de meios a fins. A parte da Teoria do Estado ou da Ciência Política que tem por tarefa o estudo dos valores e dos fins do Estado e dos meios de sua realização denomina-se Política, mas "strictu senso". A parte destinada ao estudo do embasamento social da entidade estatal denomina-se Teoria social ou sociológica do Estado. E, finalmente, a terceira parte da Teoria do Estado denomina-se Teoria jurídica do Estado, porque tem por objetivo o estudo do Estado como ordenamento jurídico, ou seja, a forma jurídica da organização política. 
Poderemos comparar o Estado a uma pinâmide de três faces: há uma de ordem sociológica, uma segunda de natureza jurídica e uma terceira de caráter político ou técnico-pragmatico. A cada uma dessas faces corresponde uma parte especial da Teoria do Estado, mas tôdas elas revelam a existência de uma base comum e de uma estrutura unitaria, que transcende os limites de cada uma e de tôdas as apontadas pesquisas particulares, de maneira que o estudo prévio e fundamental do Estado deve consistir em uma fenomenologia da realidade estatal (Ontognoseologia do Estado).

Determinada a natureza e a consistência da "entidade' política", caracterizada a sua estrutura à luz do duplo processo de "integração social" e de "especificação do poder", só então é que logra sentido a discriminação das partes especiais já referidas.

Na Teoria social ou sociológica do Estado estudamos a origem do Estado, as formas tipicas ou os tipos ideais cque o Estado tem assumido através do tempo. Só o estudo da formação do Estado é um estudo imenso que requer por parte dos pesquizadores conhecimentos múltiplos de Sociologia, de História, de Etnologia. Entretanto, estas ciências tôdas só fornecem material para o teórico do Estado, que tem por finalidade apreciar o Estado no seu substrato social, do ponto de vista, por assim dizer, do seu índice "convivência - comunidade".

Se passarmos à segunda ordem de estudo, que é a Teoria jurídica do Estado, encontraremos outra série de grandes problemas. Por exemplo, o problema que se levanta deante desta simples pergunta: que é constituição?

Cabe à Teoria jurídica do Estado esclarecer o que seja constituição, distinguir as espécies de constituições, e especialmente, o sentido substancial do termo "constituição", e a acepção formal do mesmo termo. Depois que o teórico do Estado determinou o conteúdo da palavra "constituição, ou o conceito do "constitucional", é que 
fica estabelecido o objeto específico de uma disciplina jurídica particular que é o Direito Constitucional.

Por isso, o Direito Constitucional não se confunde com a Teoria do Estado, nem por ela é abrangido como parte de um conglomerado. E', ao contrário, uma disciplina autônoma, cuja configuração rigorosa implica em uma concepção prévia do Éstado.

Outro grande problema estudado pela Teoria Geral do Estado é o problema da soberania. Isto talvês cause certa estranheza, porquanto no estudo do Direito Constitucional tem-se oportunidade de debater o problema. ¿́. que todo professor de Direito Constitucional não pode prescindir de elementos de Direito Público em geral, e de elementos de Teoria do Estado, para possibilitar o estudo especializado que tem em vista.

Entretanto, vários constitucionalistas procuram apresentar uma teoria puramente juríidica da soberania. Daí haver muitas disputas e equívocos. Talvez a confusão reinante quanto ao tema da soberania resulte, em grande parte, da pretensão que tiveram e têm os constitucionalistas de resolver, em termos exclusivamente jurídicos, um problema que transcende à esfera do Direito, por apresentar aspectos políticos, éticos, sociológicos, históricos.

Foi a moderna elaboração da Política ou da Teoria do Estado que possibilitou melhores esclarecimentos sôbre o que se deve entender por soberania. Esta é uma categoria histórica do poder. A "sociedade urbana" dos gregos, a "polis" era, sem dúvida alguma, um Estado, como nô-lo demonstra a história de Atenas ou de Esparta. Entretanto, a Grécia não conheceu "soberania", assim como Roma não uniu tal conceito ao de "imperium" ou ao de "majestas".

A soberania é uma forma especial do fenômeno genérico do poder que surge no início da época moderna. Foram estudos de natureza complexa, como os de Jellinek, que vieram a demonstrar o característico especial da so- 
berania, porquanto não podia tal argumento ser apreciado segundo prismas estritamente jurídicos, sem grave deformidade, o que ocorre, aliás, com a Teoría do Estado puramente iuridica:

A soberania é, como o Estado, um fenômeno complexo, que apresenta aspectos políticos, sociológicos e jurídicos. Jurídicamente a soberania é, a nosso ver, o poder originário de declarar a positividade do Direito em última instância, e não é mais do que isso.

Entretanto, essa visão jurídica da soberania não nos dá senão um dos momentos do problema do poder, que exige outras luzes para a sua clara compreensão, não podendo ser situado fóra do processo formador do chamado "Fistado Moderno".

Designamos com a expressão "Estado Moderno" a forma especial de Estado constituida com o desmembramento da unidade política que teòricamente existia na Idade Média, resultando da aglutinação e da autonomia dos nucleos culturais que na realidade formavam ilhas dispersas daquela estrutura social e econômica. Não podemos tratar desta questão, que não se contém no campo deste trabalho, mas estas considerações já bastam para mostrar que a Teoria do Estado tem um conjunto de problemas específicamente seus, que não se confundem com os problemas do Direito Constitucional, do Direito Administrativo, ou da Ciência da Administração.

Ao contrário, o trabalho do constitucionalista, ou do estudioso da Ciência da Administração começa exatamente quando termina o trabalho do teórico do Estado, visando resolver problemas em relação ao Estado atual, e mais precisamente, com referência a uma forma particular de Estado.

Como se vê, os problemas da Teoria do Estado envolvem, necessáriamente, problemas de Teoria da Direito, embora os campos respectivos se martennam claramente distintos. 


\section{Teoria do Estado e Filosofia do Direito.}

Dizer, no entanto, que a Teoria do Estado não se confunde com a Teoria do Direito não importa em resolver o problema da Filosofia do Direito perante a Teoria do Estado.

O teórico do Estado mantem-se sempre no plano fenomenal ou empírico, procurando compreender a realidade estatal segundo categorias de espaço e de tempo. Por mais que generalize, que avance na generalização, tem sempre diante de si o Estado como um dado que se lhe oferece na história. O filósofo do Direito vai além dessa posição, porque indaga das razões da existência do próprio poder, do próprio Estado. O problema filosófico do Estado é o problema filosófico do poder, da autoridade e da liberdade em uma coexistência ordenada. Isto quer dizer que, no plano filosófico, na esfera das cogitações universais, existe uma convergência entre a pesquisa do Estado e a pesquisa do Direito.

Tôda Filosofia do Direito implica em uma Filosofia do Estado ou Filosofia Política. É por isso que dizemos sempre que a mais exata denominação de nossa disciplina seria esta: Filosofia do Direito e do Estado. A rigor, é o que se observa pela leitura de obras fundamentais de Filosofia do Direito, desde Kant e Hegel a Stammler e Del Vecchio, onde se encontram, lado a lado, os problemas do Direito el os do Estado.

É que, no fundo, Direito e Estado são duas faces de uma única realidade. Se penetrarmos na essência da vida associativa, veremos que o problema do Direito é inseparável do problema do Estado, de sorte que a cogitação filosófica sôbre o primeiro implica necessảriamente na pesquisa filosófica do outro. Quem esclarece bem esta questão é Jean Dabin, na primeira parte de seu livro Doutrina Geral do Estado. Nesta obra mostra-nos como a co- 
gitação filosófica do Estado è a cogitação filosófica do Direito. Daí o sub-título sugestivo que deu a seu trabalho: "Elementos de Filosofia Jurídica". Êle quer dizer, com essa expressão, que se levarmos a Teoria Geral do Estado ao plano de seus pressupostos, encontrar-nos-emos na órbita mesma da especulação filosófico-jurídica. Daí a impossibilidade de incluir-se a Filosofia Política no âmbito da Ciência Política, a qual, sendo ciência de realidade, não pode deixar de ser considerada empiricamente.

Não me parece, por fim, que qualquer indagação de elementos axiológicos na problemática do Estado tenha necessáriamente caráter filosófico: uma cousa é indagar dos valores e dos fins condicionantes da realidade estatal (objeto da Filosofia Política); outra é apreciar tais valores "in concreto", como experiência axiológica, na condicionalidade dos ciclos de cultura, tendo em vista a interferência normativa do Poder, segundo critérios empíricos de oportunidade e de conveniência, com se faz no que chamo Teoria política do Estado, em cujo âmbito se inclue a Política do Direito.

É claro que estas distinções não implicam no desconhecimento de que entre Teoria do Direito e Teoria do Estado, própriamente ditas, existe, por assim dizer, uma zona "cinzenta" que comporta questões que dificilmente poderiam ser separadas ou distintas. Esta zona cinzenta (para empregarmos uma expressão característica de Barassi em relação ao Direito Público e ao Direito Privado) é tão vasta que nos julgamos em condições de escrever um livro Teoria do Direito do Estado que tem por objetivo o estudo dos problemas conexos, posta a questão no plano empírico, em face dos "dados" estatais que ao jurista cumpre analisar.

Em resumo, podemos dizer que a Ciência do Direito e a Ciência do Estado são ciências de realidades culturais cujos valores e estruturas implicam em indagações de ordem. filosófica entre si inseparáveis. 